\title{
Perfil de resistência antimicrobiana de isolados de Escherichia coli obtidos de águas superficiais e subterrâneas, em área de produção de suínos
}

\author{
Roger Neto Schneider \\ André Nadvorny \\ Verônica Schmidt* \\ Setor de Medicina Veterinária Preventiva, Faculdade de Medicina Veterinária \\ Universidade Federal do Rio Grande do Sul \\ CEP 91540-000, Porto Alegre - RS, Brasil \\ *Autor para correspondência \\ veronica.schmidt@ufrgs.br
}

Submetido em 30/10/2008

Aceito para publicação em 26/04/2009

\section{Resumo}

A utilização de antimicrobianos, de maneira excessiva e indiscriminada na produção animal intensiva, tem desencadeado o aumento no número de microrganismos resistentes, os quais podem ser transportados para ambientes aquáticos. O objetivo do presente estudo foi determinar o perfil de resistência a antimicrobianos de isolados de Escherichia coli obtidos de águas subterrâneas e superficiais em região de produção de suínos. Através do teste de suscetibilidade antimicrobiana foram analisadas 205 linhagens de $E$. coli. Observou-se, maior índice de resistência ao cefaclor tanto em águas superficiais $(51,9 \%)$ quanto subterrâneas $(62,9 \%)$, enquanto todas as amostras foram sensíveis à amicacina. O percentual de amostras multirresistentes foi de $25,96 \%$ e $26,73 \%$ em águas superficiais e subterrâneas, respectivamente; enquanto 19,23\% e 13,86\% foram sensíveis a todos os antimicrobianos testados. Determinou-se que o índice de resistência múltipla aos antimicrobianos (MAR) foi de 0,164 para águas superficiais e 0,184 para subterrâneas. Não foram verificadas diferenças significativas no perfil de resistência a antimicrobianos em linhagens de E. coli isoladas em água superficiais e subterrâneas, mas o índice MAR calculado em pontos de água subterrânea podem oferecer risco potencial de transmissão de genes de resistência.

Unitermos: água subterrânea, água superficial, Escherichia coli, resistência antimicrobiana

\section{Abstract}

Antibiotic resistance patterns of Escherichia coli strains isolated from surface water and groundwater samples in a pig production area. The use of antibiotics, so excessive and indiscriminate in intensive animal production, has triggered an increase in the number of resistant microorganisms which can be transported to aquatic environments. The aim of this study was to determine the profile of the antimicrobial resistance of samples of Escherichia coli isolated from groundwater and surface water in a region of pig breeding. Through the test of antimicrobial susceptibility, we analyzed 205 strains of $E$. coli. A high rate of resistance to cefaclor was observed, both in surface water $(51.9 \%)$ and groundwater $(62.9 \%)$, while all samples were sensitive to 
amikacin. The percentages of multi-resistant samples were $25.96 \%$ and $26.73 \%$ in surface water and groundwater, respectively, while $19.23 \%$ and $13.86 \%$ were sensitive to all antibiotics tested. It was determined that the rate of multiple antibiotic resistance (MAR) was 0.164 for surface water and 0.184 for groundwater. No significant differences were found in the profile of the antimicrobial resistance in strains of $E$. coli isolated in surface water and groundwater, but the index MAR calculated in certain points of groundwater may offer a potential risk of transmission of resistant genes.

Key words: antibiotic resistance, Escherichia coli, groundwater, surface water

\section{Introdução}

As atividades agrícolas relacionadas à produção animal intensiva têm sido apontadas como a maior fonte de poluição fecal em águas superficiais e subterrâneas (Parveen et al., 2005). A utilização de antimicrobianos, de maneira excessiva e indiscriminada na produção animal intensiva, tem desencadeado o aumento no número de microrganismos resistentes (Harakeh et al., 2006), os quais podem ser transportados para o solo, alimentos e ambientes aquáticos (Mckeon et al., 1995).

Entre as bactérias presentes no ambiente, o grupo dos coliformes tem sido extensivamente utilizado como um indicador da qualidade da água. Entre os coliformes, a contagem de Escherichia coli é considerada uma das melhores técnicas para estimar o grau de poluição fecal (Yáñez et al., 2006). Amostras de E. coli resistentes a antimicrobianos têm sido observadas em águas subterrâneas (Mckeon et al., 1995; Gallert et al., 2005), rios (Boon e Cattanach, 1999; Webster et al., 2004) e esgoto (Reinthaler et al., 2003).

Nos humanos, linhagens patogênicas de E. coli têm sido identificadas como causa primária de infecções no trato urinário, meningite neonatal, septicemia nosocomial e enterites. A resistência à pelo menos duas classes de antimicrobianos tem sido um achado comum tanto na medicina humana quanto veterinária, restringindo as opções terapêuticas disponíveis (Von Baum e Marre, 2005).

No Brasil, a produção de suínos ocorre em todas as regiões, especialmente na Região Sul (43,7\%), sendo o Estado de Santa Catarina o principal produtor nacional (17,46\%). O município de Concórdia possui o terceiro maior rebanho suíno do país com mais de 513 mil cabeças (IBGE, 2006). Esta região caracteriza-se pela criação intensiva de suínos, especialmente em pequenas propriedades que utilizam mão-de-obra familiar (Pertile, 2001), com armazenamento de dejetos em esterqueiras, para posterior utilização como adubo no solo (FATMA, 2003). Em trabalhos anteriores, observou-se perfil de multirresistência em amostras de E. coli isoladas em esterqueiras nesta região (Santos et al., 2006; Silva et al., 2008) e considerando a possibilidade de veiculação de microrganismos entéricos aos mananciais hídricos, após a disposição de dejetos no solo, o presente trabalho teve como objetivo avaliar o perfil de resistência a antimicrobianos de amostras de $E$. coli isoladas em águas subterrâneas e superficiais, na região rural do Município de Concórdia, estado de Santa Catarina.

\section{Material e Métodos}

Foram realizadas sete coletas em 18 pontos com um intervalo médio de duas semanas. Para cada amostra, foram coletadas cerca de $100 \mathrm{~mL}$ de água, em frascos de vidro estéreis. Após a coleta, o material foi identificado e acondicionado em caixas isotérmicas contendo gelo e encaminhado ao Laboratório de Medicina Veterinária Preventiva, da Universidade Federal do Rio Grande do Sul, para processamento, após $24 \mathrm{~h}$ de transporte.

As amostras foram organizadas em dois grupos segundo a origem: subterrânea ou superficial. As amostras de água subterrânea eram provenientes de poços artesianos (seis), fontes utilizadas nas atividades de produção animal e doméstica (quatro) e de piezômetro (uma); as águas superficiais (sete) eram provenientes de pontos escolhidos aleatoriamente ao longo do rio Lajeado - Suruví. Essa microbacia situa-se nos quadrantes sul e sudeste do município de Concórdia e é afluente do rio Uruguai, com desembocadura no lago formado pela usina hidrelétrica de Itá. 
A partir da técnica dos tubos múltiplos para determinação do número mais provável de coliformes (Franson, 1995), as amostras positivas no caldo EC foram semeadas em ágar eosina azul de metileno e incubadas à $37^{\circ} \mathrm{C}$ por $24 \mathrm{~h}$ sendo, posteriormente, selecionadas três colônias típicas (colônias esverdeadas, com brilho metálico e geralmente com centro mais escuro), de forma aleatória. As colônias, identificadas por testes bioquímicos de rotina (Quinn et al., 1998; Mac Faddin, 2000), foram mantidas em caldo cérebro coração (BHI), com $20 \%$ de glicerol à $-20^{\circ} \mathrm{C}$ até o momento da realização do teste de sensibilidade aos antimicrobianos.

Duzentas e cinco cepas foram testadas quanto à resistência a antimicrobianos utilizando-se o método de difusão em ágar (ANVISA, 2005). Foram utilizados discos (Cecon) impregnados com os seguintes antimicrobianos: ácido nalidíxico $(30 \mu \mathrm{g})$, amicacina $(30 \mu \mathrm{g})$, amoxacilina/ ácido clavulânico $(20 / 10 \mu \mathrm{g})$, ampicilina $(10 \mu \mathrm{g})$, cefaclor $(30 \mu \mathrm{g})$, ciprofloxacina $(5 \mu \mathrm{g})$, cloranfenicol $(30 \mu \mathrm{g})$, estreptomicina $(10 \mu \mathrm{g})$, gentamicina $(10 \mu \mathrm{g})$, neomicina $(30 \mu \mathrm{g})$, sulfonamida $(300 \mu \mathrm{g})$, tetraciclina $(30 \mu \mathrm{g})$, tobramicina $(10 \mu \mathrm{g})$ e trimetropima $(5 \mu \mathrm{g})$. O teste qualitativo dos discos foi realizado previamente com uma cepa referência de Eschericha coli ATCC 25922.
O índice de resistência múltipla aos antimicrobianos (MAR) foi calculado separadamente para cada grupo (subterrânea ou superficial) através da fórmula $\mathrm{a} /(\mathrm{b} \mathrm{x}$ c), onde $a$ é o escore de resistência agregada de todas as amostras de $E$. coli pertencentes ao grupo; $b$ é o número de antimicrobianos testados no estudo e $c$ é o número de amostras de E. coli no grupo testado (Krumperman, 1983; Kaspar e Burges, 1990).

As diferenças significativas entre resistência antimicrobiana nos grupos e entre coletas foram determinadas pelo teste exato de Fischer, utilizando-se o programa GraphPad Prism 4.0., aplicando um nível de significância de 5\%.

\section{Resultados e Discussão}

Das 77 amostras de água superficial e 49 de água subterrânea analisadas, foram isoladas e identificadas 205 isolados de E. coli. Os percentuais de resistência encontrados aos 14 antimicrobianos testados estão apresentados na Tabela 1. Observou-se que o Cefaclor foi o antimicrobiano que apresentou maior percentual de resistência tanto em cepas isoladas em água subterrânea $(62,9 \%)$ quanto superficial (51,9\%). As 101 amostras provenientes de águas subterrâneas foram sensíveis à amicacina e as 104 , de origem superficial, foram sensíveis à amicacina e gentamicina.

TABELA 1: Percentual de resistência antimicrobiana de cepas de Escherichia coli isoladas em água, segundo a origem subterrânea e superficial.

\begin{tabular}{lccc}
\cline { 2 - 3 } \multicolumn{1}{c}{ Antimicrobiano } & $\begin{array}{c}\text { Subterrânea } \\
(\mathbf{n = 1 0 1 )}\end{array}$ & $\begin{array}{c}\text { Ouperficial } \\
(\mathbf{n = 1 0 4})\end{array}$ & $\begin{array}{c}\text { Total } \\
(\mathbf{n = 2 0 5})\end{array}$ \\
\cline { 2 - 3 } Ácido nalidíxico & 28,1 & 25,0 & 25,9 \\
Amicacina & 0 & 0 & 0 \\
Amoxaciclina/ácido clavulânico & 13,48 & 10,58 & 11,22 \\
Ampicilina & 37,1 & 36,5 & 36,1 \\
Cefaclor & 62,9 & 51,9 & 57,6 \\
Ciprofloxacina & 1,12 & 1,92 & 1,95 \\
Cloranfenicol & 16,9 & 15,4 & 15,6 \\
Estreptomicina & 12,4 & 7,69 & 9,27 \\
Gentamicina & 5,62 & 0 & 2,44 \\
Neomicina & 2,25 & 0,96 & 1,95 \\
Sulfonamida & 23,6 & 24,0 & 23,9 \\
Tetraciclina & 30,3 & 28,8 & 27,8 \\
Tobramicina & 11,2 & 8,65 & 9,27 \\
Trimetoprima & 24,7 & 18,3 & 20,5 \\
\hline
\end{tabular}


Verificou-se que $86,14 \%$ das linhagens de $E$. coli isoladas em água subterrânea foram resistentes à pelo menos um antimicrobiano. Também Mckeon et al. (1995) encontraram elevados índices de resistência (87\%) em coliformes isolados de águas subterrâneas em uma região rural da Virgínia, Estados Unidos. Esses autores comprovaram a transferência in vitro de resistência à ampicilina entre amostras ambientais resistentes e sensíveis.

Em ambientes aquáticos, os perfis de resistência encontrados em amostras de E. coli apresentam grande variabilidade, segundo a origem da água. Em poços, localizados próximo a canos de emissão de esgotos domésticos, Gallert et al. (2005) verificaram linhagens de $E$. coli com elevados índices de resistência (>90\%) à penicilina, ampicilina e vancomicina; já, em um poço localizado a $410 \mathrm{~m}$ de distância deste ponto, observaram ausência de coliformes. Estes resultados apontam à influência da emissão de efluentes na contaminação de águas, inclusive subterrâneas e a veiculação de microrganismos resistentes implicando em risco à saúde humana e animal.

Em linhagens de E. coli provenientes de águas superficiais localizados em propriedades suinícolas, Parveen et al. (2005) observaram resistência à tetraciclina (52\%), estreptomicina (19\%) e amoxicilina (27\%), maiores do que a observada no presente estudo em águas superficiais; já os resultados observados frente ampicilina (37\%), foram semelhantes. Por outro lado, na Austrália (Boon e Catanach, 1999) e Estados Unidos (Webster et al., 2004) foram observados menores índices de resistência a antimicrobianos em bactérias isoladas em águas superficiais em zonas urbanas e rurais. Um aspecto comum observado nesses trabalhos é o baixo índice de resistência $(<10 \%)$ aos aminoglicosídeos, como neomicina, gentamicina e amicacina, o que pode ser indicativo do baixo uso desses fármacos no tratamento de infecções em animais (Tzoc et al., 2004).

Comparando o perfil de resistência aos antimicrobianos de linhagens de E. coli isoladas em diferentes ambientes, foi observado que isolados de fezes suínas apresentam maior índice de resistência do que os de rio (Sayah et al., 2005), no estado de Michigan (Estados Unidos). Também em amostras isoladas de esterqueiras (Silva et al., 2008) na região de Concórdia, os percentuais de resistência foram maiores, especialmente em relação à tetraciclina $(82,3 \%)$.

Este fato deve-se, provavelmente, à pressão de seleção exercida pelo uso do antibiótico na produção animal intensiva uma vez que tetraciclina é indicada para o tratamento de doenças causadas por microrganismos Gram negativos (Barcellos e Sobestiansky, 1998) inclusive E. coli. Outro aspecto refere-se ao ácido nalidíxico com elevado índice de resistência (64\%) em dejetos suínos (Silva et al., 2008). Esta quinolona é indicada no tratamento de doenças urinárias, devido à rápida excreção pelo rim. Entretanto, o uso de uma quinolona de primeira geração tende a desenvolver resistência aos demais antimicrobianos deste grupo (Barcellos e Sobestiansky, 1998), entre eles a ciprofloxacina.

Em amostras originárias de ambientes aquáticos, a pressão seletiva não seria tão intensa quanto na produção animal. Entretanto, deve-se considerar que além dos efluentes de sistemas de tratamento de dejetos de origem animal, também efluentes urbanos são direcionados às coleções de superfície. Por outro lado, estas servem de recursos ao abastecimento de comunidades bem como ao lazer. A transmissão de microrganismos patogênicos ao homem por veiculação hídrica já foi amplamente discutida. Bactérias resistentes a antimicrobianos podem ser encontradas no ambiente contaminado com efluente industrial, humano ou animal, local onde sofrem pressão de seleção (Linton, 1988). A coexistência de elevado número de microrganismos em ambientes poderia selecionar as linhagens mais resistentes e propiciar a troca de determinantes de resistência a antimicrobianos entre grupos de enterobactérias (Hassani et al., 1992; Mezrioui e Baleux, 1994).

$\mathrm{O}$ fato de termos observado elevado percentual de resistência ao cefaclor, no presente estudo, poderia significar, em um primeiro momento, que as cepas avaliadas não seriam, em sua maioria, de origem animal. Isto por que, esse fármaco, uma cefalosporina de primeira geração, não é utilizada em medicina veterinária; sendo que nesse grupo de antimicrobianos, o único fármaco cujo uso é permitido nos animais é o ceftiofur (Barcellos e Sobestianky, 1998), uma cefalosporina de quarta 
geração. No entanto, o desenvolvimento de resistência cruzada entre as cefalosporinas de primeira e demais gerações tem sido discutido (Sayah et al., 2005), sendo que já foram observadas amostras de isolados humanos resistentes ao ceftiofur, apesar de o mesmo não ser utilizado na medicina humana (Schroeder et al., 2002). A resistência de Enterobacteriaceae, como E. coli, a esses compostos é mediada por $\beta$-lactamases de espectro ampliado ("extended spectrum $\beta$-lactamases" ou ESBL), as quais são mediadas por plasmídios que contem genes que codificam ESBL (Garza-Ramos et al., 2007). Para identificar de forma precisa a origem dos microrganismos isolados, a ribotipagem de linhagens de E. coli poderia ser utilizada (Parveen et al., 2005).

Observou-se grande variabilidade nos perfis de resistência sendo a maioria (cerca de $70 \%$ ) representada por um único isolado, tanto em águas superficiais quanto subterrâneas, sendo que aqueles mais comumente encontrados nas amostras de água estão representados na Tabela 2. Verificou-se que resistência isoladamente ao cefaclor foi o perfil mais frequente.

Verificou-se que $14(13,86 \%)$ amostras isoladas em águas subterrâneas foram sensíveis a todos os antimicrobianos testados, enquanto 27 (26,73\%) foram resistentes a quatro ou mais antimicrobianos. Em águas superficiais, as amostras multirresistentes corresponderam a $25,96 \%$ (27), enquanto $19,23 \%$ (20) foram sensíveis a todos os antimicrobianos testados (Tabela 3).

O número de marcadores de resistência concomitantes apresentado pelas amostras de origem subterrânea variou entre um (33 amostras) e 11 antimicrobianos (uma amostra), sendo grande parte das amostras $(32,67 \%)$ resistentes a um antimicrobiano. Em linhagens isoladas de água superficial, o número de marcadores de resistência concomitantes variou entre um (30 amostras) e sete antimicrobianos (três amostras), sendo parte $(28,85 \%)$ das amostras resistentes a um antimicrobiano (Tabela 3).

O índice MAR calculado para as amostras de $E$. coli foi 0,184 em águas subterrâneas e 0,164 em águas superficiais. Krumperman (1983) definiu arbitrariamente em 0,2 o índice MAR como potencial reservatório de determinantes de resistência para E. coli. Embora se encontrem fora da faixa de risco, estão bastante próximos ao índice proposto, especialmente em águas subterrâneas. Observou-se que três pontos de água subterrânea (duas fontes e um poço artesiano) apresentaram índice MAR superior à 0,2 (Figura 1), implicando em possível risco à saúde. Desta forma, uma avaliação detalhada dos aspectos relacionados à localização, construção e manejo destes pontos deverá ser realizada a fim de qualificar estes recursos hídricos para sua plena utilização.

TABELA 2: Número de amostras e perfil de resistência a antimicrobianos de linhagens de Escherichia coli isoladas em águas superficiais e subterrâneas.

\begin{tabular}{lcc}
\hline \multirow{2}{*}{ Perfil } & \multicolumn{2}{c}{ Origem } \\
\cline { 2 - 3 } & Subterrânea & Superficial \\
\hline Cefaclor & 22 & 20 \\
Ampicilina & 3 & 3 \\
Ácido nalidixico & 3 & 3 \\
Ampicilina, cefaclor & 2 & 3 \\
$\begin{array}{l}\text { Cefaclor, sulfonamida } \\
\text { Cefaclor, tetraciclina }\end{array}$ & 3 & 1 \\
$\begin{array}{l}\text { Ampicilina, cefaclor, tetra- } \\
\text { ciclina }\end{array}$ & 3 & 1 \\
$\begin{array}{l}\text { Amoxaciclina/ácido clavu- } \\
\text { lânico, ampicilina, cefaclor }\end{array}$ & 1 & 3 \\
$\begin{array}{l}\text { Ampicilina, cefaclor, sulfo- } \\
\text { namida, tetraciclina }\end{array}$ & 3 & 2 \\
\hline
\end{tabular}

TABELA 3: Percentual de número de marcadores de resistência antimicrobiana de linhagens de Escherichia coli isoladas emágua, segundo a origem subterrânea e superficial.

\begin{tabular}{|c|c|c|}
\hline \multirow[b]{2}{*}{$\begin{array}{l}\text { Número de } \\
\text { marcadores }\end{array}$} & \multicolumn{2}{|c|}{ Origem } \\
\hline & $\begin{array}{c}\text { Subterrânea } \\
(\mathrm{n}=101)\end{array}$ & $\begin{array}{c}\text { Superficial } \\
(\mathrm{n}=104)\end{array}$ \\
\hline 0 & 13,86 & 19,23 \\
\hline 1 & 32,67 & 28,85 \\
\hline 2 & 14,85 & 12,5 \\
\hline 3 & 11,88 & 13,46 \\
\hline 4 & 3,96 & 8,65 \\
\hline 5 & 7,92 & 5,77 \\
\hline 6 & 6,93 & 8,65 \\
\hline 7 & 3,96 & 2,88 \\
\hline 8 & 2,97 & 0 \\
\hline 11 & 0,99 & 0 \\
\hline
\end{tabular}




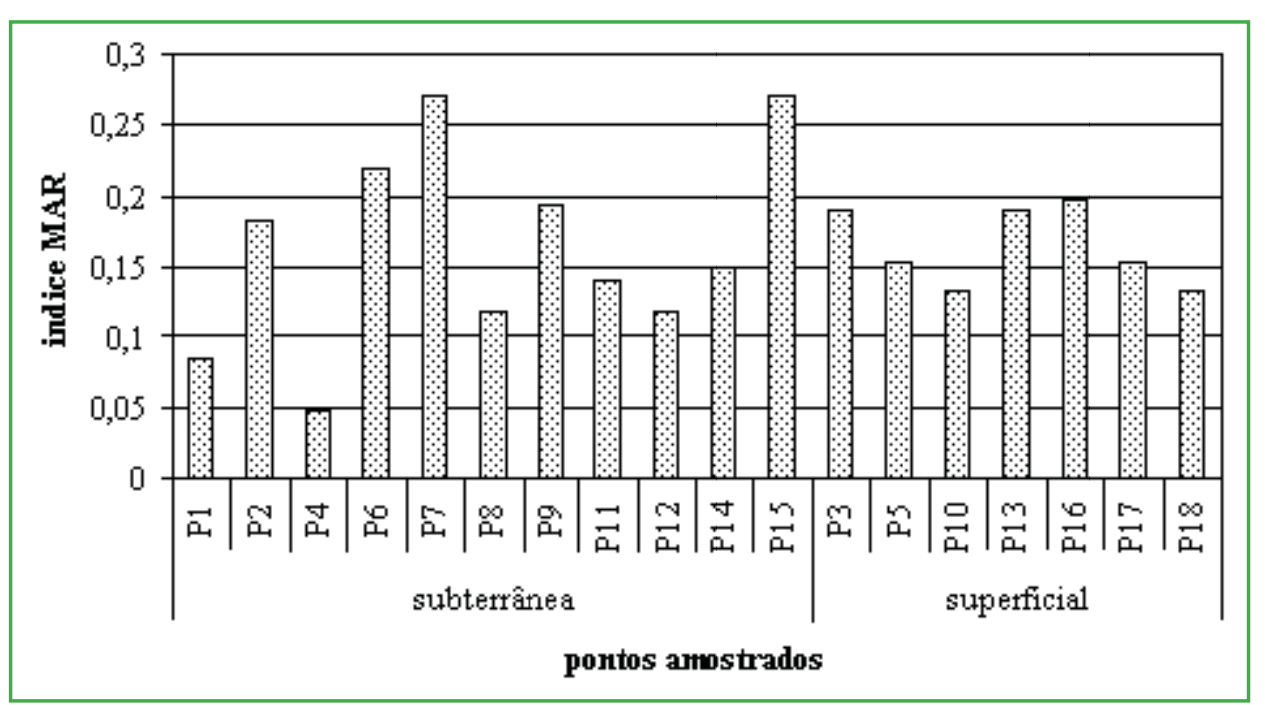

FIGURA 1: Índice de multirresisência a antimicrobianos (MAR) de linhagens de Escherichia coli isoladas em água subterrânea e superficial, segundo o ponto amostrado.

Não se evidenciou diferença significativa no perfil de resistência a antimicrobianos em isolados de E. coli isoladas em água superficiais e subterrâneas. Observou-se, pelo índice MAR calculado, que pontos de água subterrânea podem oferecer risco potencial de transmissão de genes de resistência.

\section{Agradecimentos}

À FAPERGS (processo No 03/0385.6), pelo auxílio financeiro.

\section{Referências}

ANVISA-Agência Nacional de Vigilância Sanitária. 2005. Normas de desempenho para testes de sensibilidade antimicrobiana. Disponível em <http://www.anvisa.gov.br/reblas/reblas_public_ teste_sensibilidade.pdf $>$. Acesso em 12 maio de 2006.

Barcellos, D. E. S. N.; Sobestiansky, J. 1998. Uso de antimicrobianos em suinocultura. Art3, Goiânia, Brasil, 103pp.

Boon, P. J.; Cattanach, M. 1999. Antibiotic resistance of native and fecal bacteria isolated from rivers, reservoirs and sewage treatment facilities in Victoria, south-eastern Australia. Letters in Applied Microbiology, 28: 164-168.

FATMA - Fundação do Meio Ambiente do Estado de Santa Catarina. 2003. Diário Oficial, Portaria $\mathbf{n}^{\mathbf{0}} \mathbf{0 0 2} / \mathbf{0 3}$. Governo do Estado de Santa Catarina, Florianópolis, Brasil, p.75-80.

Franson, M. A. H.(Ed.). 1995. Standard methods for examination of water and wastewater. APHA, Washington, USA, 1268pp.
Gallert, C.; Fund, K.; Winter, J. 2005. Antibiotic resistance of bacteria in raw and biologically treated sewage and in groundwater below leaking sewers. Applied Microbiology and Biotechnology, 69: 106-112.

Garza-Ramos, U.; Martínez-Romero, E.; Silva-Sánchez, J. 2007. SHV-type extended-spectrum beta-lactamase (ESBL) are encoded in related plasmids from enterobacteria clinical isolates from México. Salud Pública México, 49 (6): 415-421.

Harakaeh, S.; Yassine, H.; El-Fadel, M. 2006. Antimicrobialresistant patterns of Escherichia coli and Salmonella strains in the aquatic Lebanese environments. Environmental Pollution, 143: 269-277.

Hassani, L.; Imziln, B.; Gauthier, M. J. 1992. Antibiotic-resistant Escherichia coli from wastewater before and after treatment in stabilization ponds in the arid region of Marakech, Moroco. Letters in Applied Microbiology, 15: 228-231.

IBGE - Instituto Brasileiro de Geografia e Estatísitica. 2006. Produção Pecuária Municipal: 2006. Disponível em <http:// www.ibge.gov.br/home/estatistica/economia/ppm/2006/ppm2006. pdf $>$. Acesso em 25 de junho de 2008.

Kaspar, C. W.; Burges, J. L. 1990. Antibiotic resistance Indexing of Escherichia coli to identify sources of fecal contamination in water. Canadian Journal of Microbiology, 36: 891-894.

Krumperman, P. H. 1983. Multiple antibiotic resistance indexing of Echerichia coli to identify hihg-risk sources of fecal contamination of foods. Applied and Environmental Microbiology, 46: 165170.

Linton, A. H. 1988. Plasmids in the environment. Schriftenr ver Wasser Boden Lufthyg, 78: 197-224.

MacFaddin, J. F. 2000. Biochemical tests for identification of medical bacteria. $3^{\text {rd }} \mathrm{ed}$, Lippincott Williams e Wilkins, Baltimore, USA, 915pp.

Mckeon, D. M.; Calabrese, J. P.; Bissonnette, G. K. 1995. Antibiotic resistant gram-negative bacteria in rural groundwater supplies. Water Research, 29 (8): 1902-1908. 
Mezrioui, N.; Baleux, B. 1994. Resistance patterns of E. coli strains isolated from domestic sewage before and after treatment in both aerobic lagoon and activated sludge. Water Research, 28 (11): 2399-2406.

Parveen, S.; Lukasik, J.; Scott, T. M.; Tamplin, M. L.; Portier, K. M.; Sheperd, S.; Braun, K.; Farrah, S. R. 2005. Geographical variation in antibiotic resistance profiles of Escherichia coli isolated from swine, poultry, beef and dairy cattle farm water retention ponds in Florida. Journal of Applied Microbiology, 100: 50-57.

Pertile, N. 2001. Marcas da "integração" na agricultura familiar de Quilombo, SC. Dissertação de Mestrado, Universidade Federal de Santa Catarina, Brasil, 190pp.

Quinn, P. J.; Carter, M. E.; Markey, B.; Carter, G. R. 1998. Clinical veterinary microbiology. Harcourt Publishers Ltd, Edinburgh, Scotland, 648pp.

Reinthaler, F. F.; Posch, J.; Feierl, G.; Wust, G.; Haas, D.; Ruckenbauer, G.; Mascher, F.; Marth, E. 2003. Antibiotic resistance of Escherichia coli in sewage and sludge. Water Research, 37: 685-1690.

Santos, M. A. A.; Schmidt, V.; Bitencourt, V. C.; Maroso, M. T. D. 2006. Esterqueiras: Avaliação físico-química e microbiológica do dejeto suíno armazenado. Simpósio Internacional de Qualidade Ambiental, Porto Alegre, Brasil, CD Rom.

Sayah, R. S.; Kaneene, J. B.; Johnson, Y.; Miller, R. 2005. Patterns of antimicrobial resistance observed in Escherichia coli isolates obtained from domestic and wild-animal fecal samples, human septage, and surface water. Applied and Environmental Microbiology, 71 (3): 1394-1404.
Schroeder, C. M.; Meng, J.; Zhao, S.; DebRoy, C.; Torcolini, J.; Zhao, C.; McDermott, P. F.; Wagner, D. D.; Walker, R. D.; White, D. G. 2002. Antimicrobial resistance of Escherichia coli O26, O103, O111, O128, and O14 from animals and human. Emerging Infectious Diseases, 8 (12): 1409-1414.

Silva, F. F. P.; Santos, M. A. A.; Schmidt, V. 2008. Resistência a antimicrobianos de Escherichia coli isolada de dejetos suínos em esterqueiras. Arquivo Brasileiro de Medicina Veterinária e Zootencnia, 60 (3): 762-765.

Tzoc, E.; Arias, M. L.; Valiente, C. 2004. Efecto de las águas residuales hospitalarias sobre los patrones de resistência a antibióticos de Escherichia e Aeromonas sp. Revista Biomédica, 15: $165-172$

Von Baum, H.; Marre, R. 2005. Antimicrobial resistance of Escherichia coli and therapeutic implications. International Journal of Medical Microbiology, 295: 503-511.

Webster, L. F.; Thompson, B. C.; Fulton, M. H.; Chestnut, D. E.; Van Dolah, R. F.; Leight, A. K.; Scott, G. I. 2004. Identification of sources of Escherichia coli in South Carolina estuaries using antibiotic resistance analysis. Journal of Experimental Marine Biology and Ecology, 298: 179-195.

Yáñez, M. A.; Valor, C.; Catalán, V. 2006. A simple cost-effective method for the quantification of total coliforms and Eshecherichia coli in potable water. Journal of Microbiological Methods, 65 (3): 608-611. 